\title{
MYANIMACH - Aplikasi Mobile Untuk Membantu Binatang Yang Diabaikan
}

\author{
Siti Julianingsih Nurfitriyani ${ }^{1}$; Zaki Izzani Akbar ${ }^{2}$; Salicca Dewi Rahajeng ${ }^{3}$; Calvin Leonardo ${ }^{4}$; \\ Harco Leslie Hendric Spits Warnars ${ }^{5}$ \\ 1, 2,3, ${ }^{4}$ School of Information Systems, Universitas Bina Nusantara \\ ${ }^{5}$ Computer Science Department, BINUS, Graduate Program - Doctor of Computer Science, \\ Universitas Bina Nusantara \\ siti.nurfitriyani@binus.ac.id; zaki.akbar@binus.ac.id; salicca.rahajeng@binus.ac.id; \\ calvin.leonardo@binus.ac.id; spits.hendric@binus.ac.id
}

\begin{abstract}
Currently, there is no specific platform to manage the adoption process for stray animals in Indonesia. This paper describes the design of a Mobile Application created to address this issue in Jakarta, named myAnimach. This app allows strays and potential adopters to meet their needs easier. myAnimach provides a user-friendly, generic user interface to help them find the strays that meet their criteria or make a post about strays in their neighborhood. Users who want to adopt or offer animals to be adopted can log in or create an account on myAnimach. If the user is interested in becoming an adopter, they need to fill the adoption form. There are several stages in the adoption process. The completion of all the stages will result in an issuance of adoption letter from myAnimach. Aside from adopting animals, users can also look for adopters for their animals by filling out the upload form on the mobile application.
\end{abstract}

Keywords: Stray animals, abandoned animals, adoption, mobile application

\begin{abstract}
ABSTRAK
Saat ini, tidak ada platform khusus untuk mengelola proses pengadopsian hewan terlantar di Indonesia. Makalah ini menjabarkan desain dari aplikasi mobile bernama myAnimach, yang akan dibuat untuk mengatasi isu di atas. Aplikasi ini memungkinkan adopter untuk menemukan hewan terlantar yang bisa diadopsi dengan lebih mudah. myAnimach menyediakan user-interface yang umum dan ramah pengguna, memudahkan pengguna untuk menemukan hewan terlantar yang sesuai dengan kriteria mereka atau membuat post tentang hewan terlantar di sekitar lingkungan mereka. Pengguna yang tertarik untuk mengadopsi hewan atau menawarkan hewan untuk diadopsi dapat membuat akun dan login di aplikasi myAnimach. Jika pengguna tertarik untuk menjadi adopter, mereka harus mengisi form adopsi. Ada beberapa tahapan dalam proses adopsi, dimana saat semua prosedur telah dilakukan, myAnimach akan menerbitkan surat adopsi. Selain untuk mengadopsi hewan, pengguna juga dapat mencari pengadopsi untuk hewan mereka dengan mengisi formulir upload di aplikasinya.
\end{abstract}

Kata kunci: Hewan liar, hewan terlantar, adopsi, aplikasi mobile 


\section{PENDAHULUAN}

Hewan liar/terlantar seperti kucing dan anjing sudah menjadi pemandangan umum di lingkungan sekitar kita akhir-akhir ini. Salah satu penyebab besarnya jumlah kucing dan anjing liar/terlantar ini terlihat tidak sehat atau terjangkit suatu penyakit sehingga pemiliknya membuang hewan tersebut. [1][2][3] Hewan-hewan terlantar ini kemudian seringkali mengalami nasib yang kurang beruntung, seperti kelaparan dan bahkan diperlakukan secara tidak pantas oleh manusia. [4][5][6][7]

Dinas Ketahanan Pangan Kelautan dan Pertanian (KPKP), yang bertanggung jawab untuk urusan kelautan, pertanian, kemanan pangan, ternak dan kesehatan hewan di Jakarta, telah mencacat lebih dari 30.000 populasi kucing liar di ibukota pada tahun 2018. Penduduk setempat melaporkan bahwa mereka mulai merasa terganggu oleh kucing liar tersebut, memaksa pemerintah untuk mengurangi jumlah kucing liar dengan berbagai cara. Penduduk disarankan untuk mengebiri kucing dan anjing mereka untuk mengurangi jumlah hewan terlantar. Beberapa penduduk setempat juga telah membuat shelter untuk menampung hewan-hewan tersebut sementara. Pada umumnya, sheltershelter juga menawarkan adopsi untuk hewan-hewan yang ditampungnya.

Di Jakarta sendiri, masih banyak orang yang benar-benar peduli dengan hewan terlantar ini dan ingin memberikan kehidupan dan rumah baru yang lebih baik bagi mereka. Namun, seringkali terdapat beberapa faktor yang menyebabkan mereka tidak mendapat informasi yang cukup akan hewan-hewan terlantar tersebut sehingga kebanyakan orang bergantung pada informasi di media sosial untuk menemukan hewan yang dapat diadopsi. Sayangnya, karena informasi dari media sosial biasanya bersifat serba cepat [8], terkadang pengumuman akan hewan yang siap diadopsi tertimpa oleh post-post baru. Hal ini dapat menyebabkan calon pengadopsi tidak dapat menemukan hewan yang siap untuk diadopsi.

Dengan demikian, untuk memfasilitasi pertemuan antara hewan terlantar dengan calon pengadopsinya, kami merancang sebuah aplikasi mobile bernama myAnimach.

Makalah ini disusun sebagai berikut : di bagian kedua kami menjabarkan tentang kondisi hewan liar/ terlantar di berbagai kota besar di dunia serta penelitian sebelumnya yang telah dibuat untuk menangani masalah tersebut, di bagian ketiga kami memperkenalkan ide-ide kami tentang myAnimach, dan di bagian empat kami menguraikan tentang bagaimana aplikasi mobile myAnimach akan bekerja dan bagaimana tampilannya akan terlihat. Makalah ini akan disimpulkan pada bagian lima.

\section{PENELITIAN SEBELUMNYA}

Saat ini, hewan terlantar telah menjadi masalah bagi banyak kota besar di berbagai negara. Kota Seoul di Korea Selatan misalnya. Seoul harus berurusan dengan 13.000 hewan terlantar setiap tahunnya. Faktanya, pada tahun 2013 dari total 11.320 hewan terlantar, $7.772(68,66 \%)$ adalah anjing dan $3.548(31,34 \%)$ adalah kucing. [9] Hewan yang terlantar menimbulkan masalah sosial, karena seringnya hewan tersebut terjangkit penyakit menular seperti Toxcara Canis dan rabies pada anjing. Penyakit tersebut dapat menular ke manusia dari luka gigitan, atau air minum yang terkontaminasi dari mayat hewan terlantar tersebut. Selain itu, sumber daya keuangan dan manusia yang diperlukan terus meningkatkan, sejak penerapan UU Perlindungan Hewan, yang mengatur pengelolaan hewan terlantar dari penangkapan hingga perawatan. Menurut UU Perlindungan Hewan, ditinggalkannya seekor hewan dapat dilaporkan ke kantor distrik. Petugas distrik pergi ke tempat dimana hewan terlantar tersebut ditemukan, menangkap, membawa ke shelter di distrik tersebut, dan membuat pengumuman tentang hewan tersebut selama 7 hari, agar pemiliknya mengetahui lokasi hewan miliknya dan dapat mengambil kembali hewan tersebut (Animal Care Management System, 
http://www.animal.go.kr). Jika pemiliknya tidak muncul dalam waktu 10 hari sejak hari pengumuman, Petugas Distrik mengambil alih kepemilikan hewan dan menetapkan rencana pascamanajemen, yang mencakup adopsi, kematian alami maupun euthanasia. [10][11]

Tingginya jumlah hewan terlantar juga dapat menyebabkan tindak kekerasan terhadap hewan, yang dapat berupa kekerasan fisik seperti memukul atau menendang hingga hewan-hewan tersebut mengalami trauma, cacat fisik, bahkan kematian maupun kekerasan psikologis seperti tidak memberi kasih sayang yang cukup, mengabaikan kebutuhannya, dan mengurung atau mengikat secara berlebihan [12][13][14][15]. Dan pada faktanya, di Indonesia sebagian besar penduduknya kurang paham tentang kekejaman terhadap hewan dan seringkali menyiksa mereka hanya karena merasa terganggu oleh hewan liar/terlantar tersebut [16][17]. Ada upaya untuk mengurangi jumlah kekejaman terhadap hewan di Pulau Jawa dengan merancang iklan layanan masyarakat. [18]

Di sisi lain, di Malaysia ada banyak penangkap anjing pribadi yang tidak peduli dengan metode yang mereka gunakan untuk menangkap anjing liar. Hal ini dikarenakan mereka menerima upah tergantung dengan jumlah anjing liar/terlantar yang berhasil mereka tangkap, buang, dan bunuh. Penangkap anjing ini menggunakan metode yang kejam untuk menangkap anjing-anjing liar tersebut, seperti memakai tongkat dan tali-tali, yang berpotensi tinggi akan menyakiti anjing-anjing yang mereka tangkap. Hanya saja, masalah yang timbul akibat meningkatnya jumlah hewan terlantar juga perlu ditangani. Untuk mencegah bertambahnya jumlah hewan liar/terlantar, ada upaya untuk mengembangkan aplikasi seluler yang dapat menemukan hewan yang terlantar/hilang dan mengembalikannya kepada pemilik masing-masing di Malaysia. [19]

Sementara di Indonesia, telah ada penelitian sebelumnya yang mencoba untuk mengatasi masalah hewan terlantar di Surabaya dengan membuat Surabaya Animal Care Community (SACC). Tujuan mereka adalah untuk menyelamatkan dan melindungi hewan terlantar. Hewan terlantar yang mereka temukan dan selamatkan, kemudian akan dirawat dan divaksinasi oleh SACC, yang selanjutnya dapat diadopsi. SACC membuat sebuah situs web dan aplikasi mobile bernama Ani-care untuk membantu melaporkan hewan terlantar dan mengumumkan hewan terlantar yang siap diadopsi. Dengan sistem yang mereka gunakan saat ini, SACC menghadapi beberapa masalah seperti sistem pelaporan yang hanya satu arah (pelaporan hanya masuk ke admin SACC), tidak adanya katalog online untuk hewan yang siap diadopsi, dan pembukuan keungan yang masih bersifat manual [20]. Dengan pengembangan situs web dan aplikasi mobile Ani-care ini, SACC berharap mereka dapat memiliki katalog online untuk anjing dan kucing liar, halaman admin untuk mengelola situs web, formulir online untuk proses adopsi, daftar donasi online, dan sistem pelaporan hewan terlantar lebih sederhana yang dapat dilihat oleh semua anggota SACC. Setelah menguji situs web dan aplikasi mobilenya, dapat diketahui bahwa Ani-care telah berfungsi sebagaimana mestinya. [21]

\section{IDE GAGASAN}

Dengan meningkatnya pengguna smartphone beberapa tahun terakhir ini, perangkat seluler adalah alat yang sangat cocok untuk mempromosikan aplikasi baru ini [22][23][24]. myAnimach adalah aplikasi yang memungkinkan orang yang ingin menawarkan hewan untuk diadopsi dan calon pengadopsi untuk memenuhi kebutuhan mereka dengan lebih mudah. Selain menyediakan platform bagi pengadopsi yang mencari jalan untuk diadopsi, myAnimach dikembangkan dengan maksud sebagai berikut:

1) Mengurangi jumlah hewan terlantar

2) Mengurangi jumlah euthanasia

3) Mengurangi jumlah kekerasan terhadap hewan 
A. Persyaratan Fungsional

Persyaratan fungsional menggambarkan interaksi antara sistem dan penggunanya. Sistem ini memungkinkan berbagai jenis pengguna untuk berinteraksi dengan aplikasi sesuai dengan hak istimewa yang diberikan. Ada dua aktor utama: pengguna dan admin. Sistem menyediakan berbagai layanan untuk setiap pengguna seperti yang ditunjukkan pada Gambar 1 diagram use case:

1) myAnimach memberi pengguna layanan seperti mendaftarkan akun, memilih hewan untuk diadopsi, mengisi formulir adopsi, dan menyediakan artikel-artikel tentang hewan.

2) myAnimach memberikan layanan kepada admin seperti membuat formulir wawancara, membuat formulir kunjungan rumah, dan membuat formulir blacklist.

\section{B. Use Case dan Database Model Class Diagram myAnimach}

Kami menggunakan diagram $U M L$ sebagai alat untuk membantu kami membangun sistem kami. Unified Modeling Language (UML) adalah bahasa untuk memvisualisasikan, menentukan, membangun, mendokumentasikan artefak dari sistem intensif perangkat lunak [25]. Diagram UML pertama yang kami gunakan adalah use case diagram. Use Case Diagram adalah diagram yang mengidentifikasi serangkaian tindakan yang dapat dijalankan oleh satu sistem dalam skenario, dan aktor, yang mewakili faktor eksternal (pengguna atau sistem eksternal) yang berinteraksi dengan sistem [26].

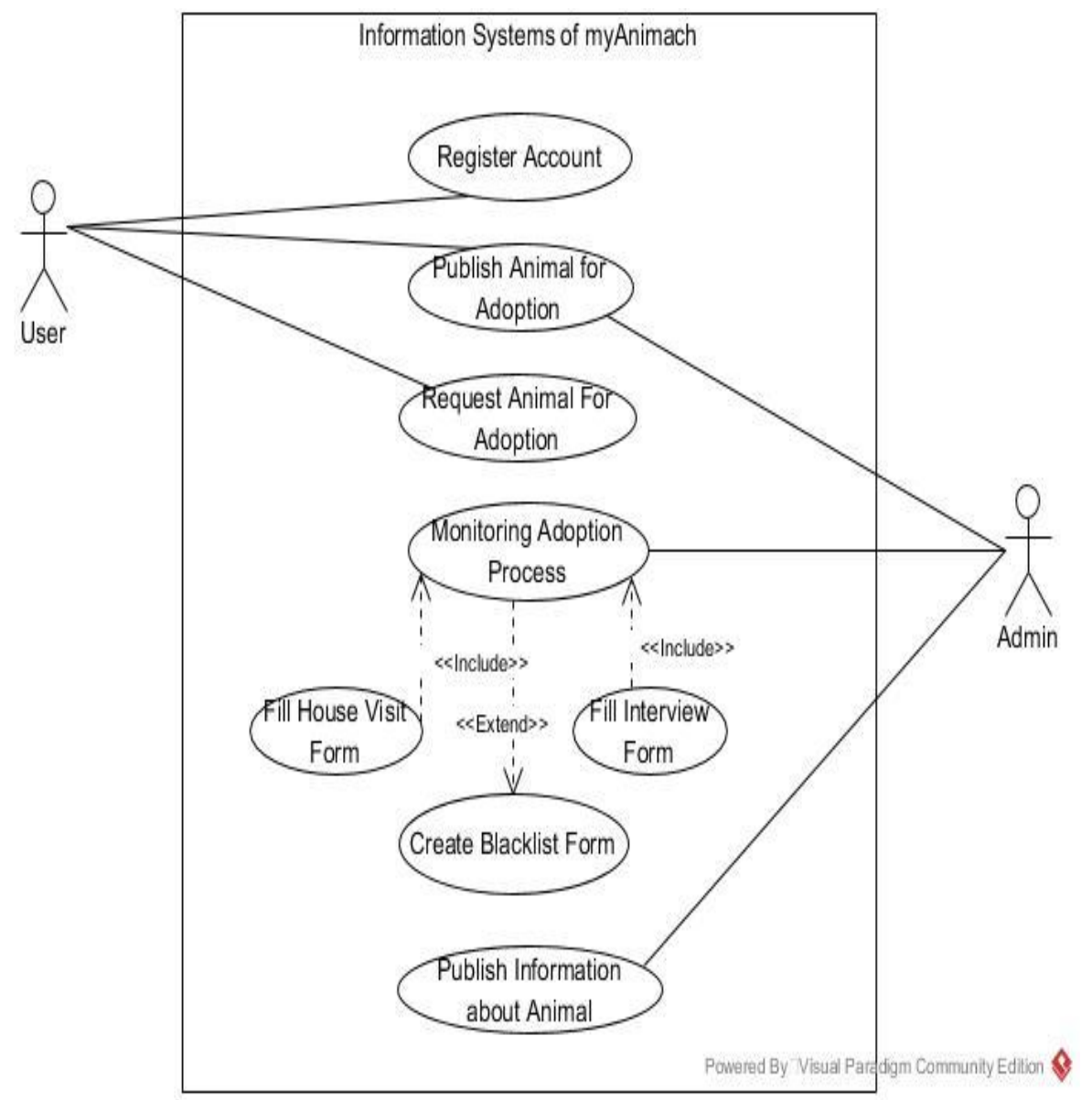

Gambar 1. Use Case Diagram of myAnimach 
Sistem yang kami usulkan memiliki diagram use case seperti yang dapat dilihat pada Gambar 1, di mana antarmuka pengguna dapat dilihat di bawah:

1) Register Account

Ketika pengguna membuka aplikasi MyAnimach, halaman sambutan akan muncul, seperti terlihat pada Gambar 2.

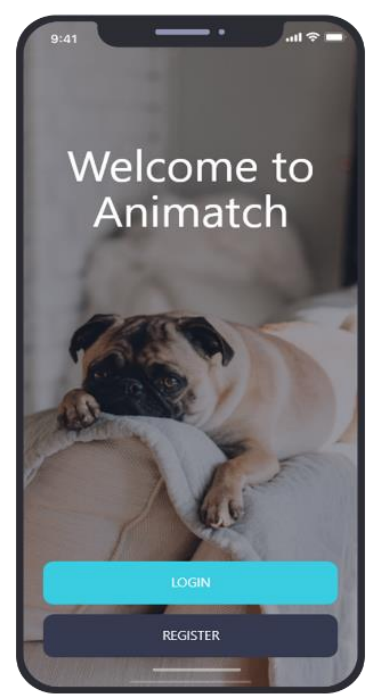

Gambar 2. Welcoming Page

Setelah itu, jika pengguna ingin mengadopsi atau menawarkan hewan untuk diadopsi, pengguna harus $\log$ in atau membuat akun terlebih dahulu di aplikasi myAnimach. Pada Gambar 3 (a), pengguna dapat mengisi email dan kata sandi mereka untuk masuk ke aplikasi. Jika mereka belum memiliki akun, pengguna dapat mendaftar ke aplikasi, seperti yang terlihat pada Gambar 3 (b). Data yang diperlukan untuk pengguna saat mendaftarkan akun adalah nama, email, kata sandi, nomor telepon, dob dan alamat. Kemudian, sistem akan secara otomatis menghasilkan id untuk pengguna.

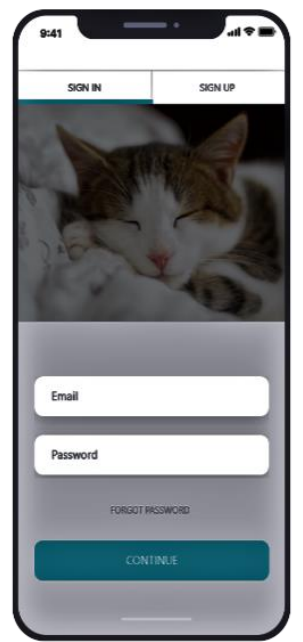

3(a)

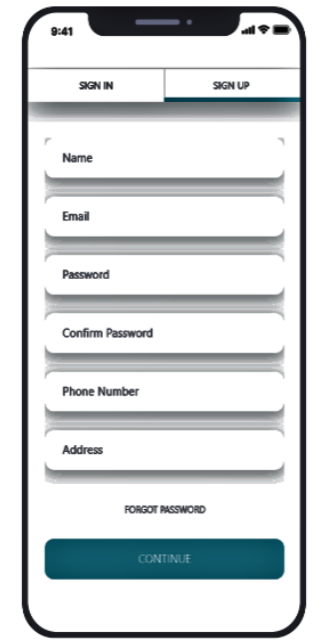

3(b)

Gambar 3. 3(a)Sign in Page, 3(b) Sign up Page 


\section{2) Request Animal for Adoption}

Setelah log in, pengguna dapat melihat hewan di aplikasi myAnimach berdasarkan kategori, seperti yang terlihat pada Gambar 4 (a). Pengguna dapat memilih hewan yang mereka minati seperti terlihat pada Gambar 4 (b) dan melihat detailnya pada Gambar 4 (c). Jika pengguna tertarik untuk menjadi calon pengadopsi untuk hewan tersebut, maka calon pengadopsi dapat bertanya lebih lanjut kepada pemilik hewan melalui fitur obrolan seperti yang terlihat pada Gambar 4 (d). Kandidat pengadopsi dapat melihat status adopsi mereka pada menu status pada Gambar 4 (e). Setiap perubahan status akan diperbarui oleh admin.

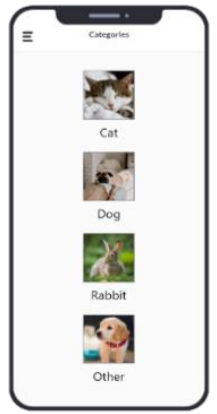

4(a)

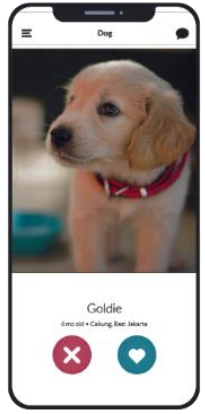

4(b)

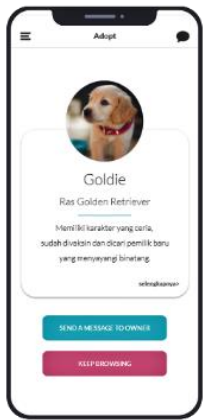

$4(\mathrm{c})$

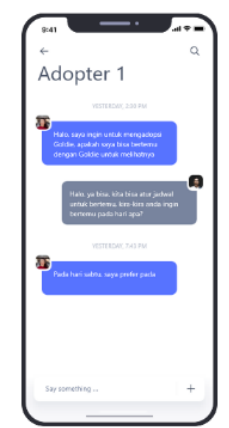

$4(\mathrm{~d})$

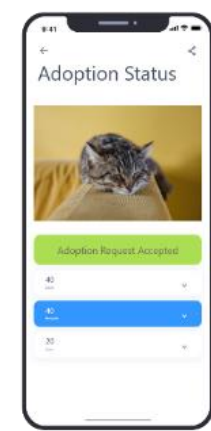

$4(\mathrm{e})$

Gambar 4. 4(a) Animal Categories, 4(b)Choose Animal, 4(c) Detail Animal, 4(d) Chat, 4(e) Adoption Status

\section{3) Publish Animal for Adoption}

Setelah $\log$ in, pengguna dapat melihat hewan-hewan yang ada di aplikasi myAnimach. Hewan-hewan yang terdapat dalam aplikasi myAnimach adalah hewan yang diunggah oleh pengguna yang ingin menawarkan hewan peliharaan mereka untuk diadopsi atau hewan yang disimpan oleh tim myAnimach dan kemudian diunggah oleh admin. Jika pengguna ingin menawarkan hewan peliharaan mereka untuk diadopsi, mereka harus mengisi formulir unggahan. Data yang diperlukan untuk mengunggah hewan peliharaan yang ditawarkan untuk diadopsi adalah nama, deskripsi, dan foto hewan.

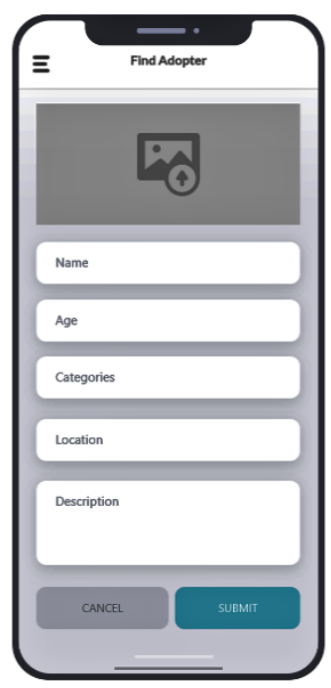

Gambar 5. Upload Animal to be Offered for Adoption

Berdasarkan aktivitas itu, desain antarmuka pengguna yang kami buat agar pengguna mengunggah hewan yang akan ditawarkan untuk diadopsi dapat dilihat pada Gambar 5. 


\section{4) Monitoring Adoption Process}

Dalam jangka waktu 3 hari, calon pengadopsi akan dipanggil untuk tahap wawancara mengenai keadaan rumah dan pengetahuan serta pengalaman calon pengadopsi tentang perawatan hewan yang akan dia adopsi. Setelah melakukan wawancara, calon pengadopsi dihubungi oleh admin untuk kunjungan rumah. Kunjungan rumah dapat diadakan kapan saja, sehingga admin dan pemilik hewan sebelumnya dapat melihat kondisi rumah seperti apa adanya. Itu akan dimasukkan pada formulir pemantauan seperti yang terlihat pada Gambar 6 (a). Jika adopter telah berhasil lulus tes, tim myAnimach akan membuat surat adopsi dengan tanda tangan dan meterai untuk pengadopsi dan pemilik hewan sebelumnya. Surat adopsi juga termasuk pengadopsi data. Jika penyimpangan mencurigakan ditemukan dan terbukti benar, maka tim myAnimach memiliki hak untuk mencabut hak adopsi pengadopsi dan membawa kembali hewan yang telah diadopsi. Admin kemudian mengisi formulir blacklist yang berisi data tentang pengguna dan penyebab pengguna pada blacklist seperti yang terlihat pada Gambar 6 (b). Blacklist dibuat untuk mencegah kondisi adopsi yang serupa.

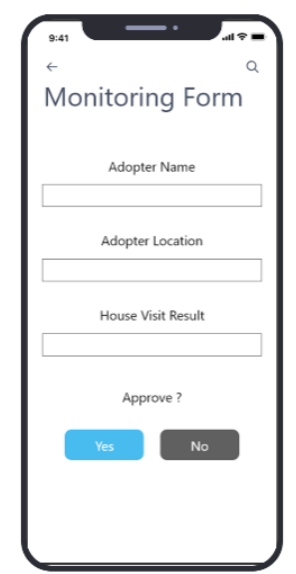

6(a)

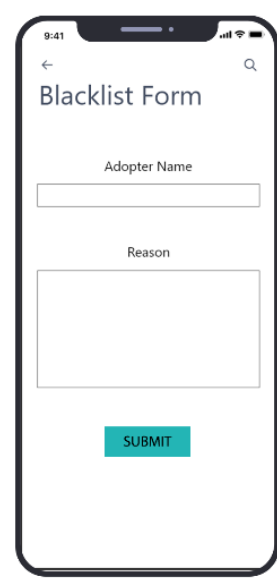

6(b)

Gambar 6. 6(a) Monitoring Form, 6(b) Blacklist Form

\section{5) Publish Article about Animal}

Selain itu, pada menu artikel, ada informasi berguna seperti tips merawat hewan peliharaan dan sebagainya. Antarmuka pengguna yang kami desain untuk menu artikel dapat dilihat pada Gambar 7 di bawah ini.

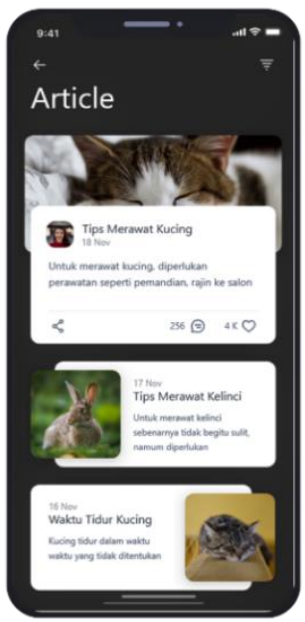

Gambar 7. Article Menu 
Diagram UML berikutnya adalah class diagram. Class diagram menggambarkan hubungan antara objek yang terlibat dalam sistem, class diagram dapat menunjukkan operasi dan properti dalam suatu objek [10].

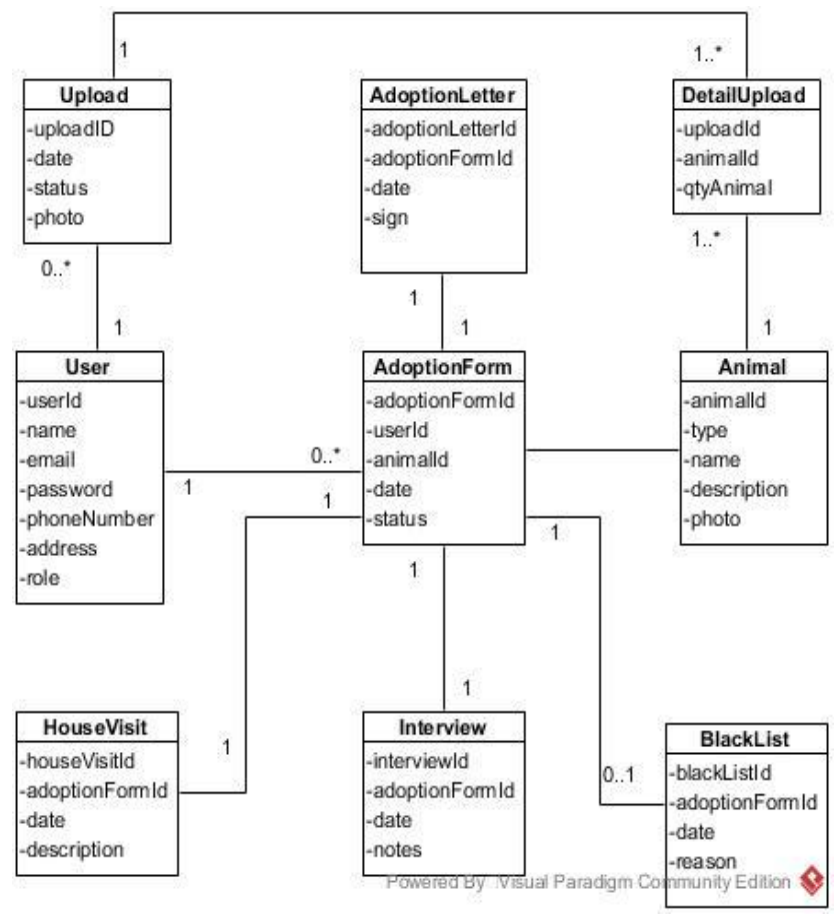

Gambar 8. Database Model Class Diagram myAnimach

Gambar 8, menyajikan dari sistem MyAnimach yang menunjukkan hubungan antara masing-masing kelas atau tabel yang saling berhubungan. Database Model Class Diagram untuk Sistem Adopsi di myAnimach ditunjukkan oleh beberapa kelas atau tabel. Tujuan diagram ini adalah untuk menunjukkan dan menjelaskan hubungan antara objek atau tabel yang terlibat dalam sistem adopsi hewan dalam aplikasi myAnimach.

Dapat dilihat bahwa pengguna dapat memiliki minimum 0 dan maksimum banyak formulir adopsi. Sedangkan formulir adopsi hanya terkait dengan 1 pengguna. Maka formulir adopsi hanya dapat berisi 1 hewan. Dan hewan hanya berurusan dengan 1 formulir adopsi. Selain itu, pengguna juga dapat memiliki setidaknya 0 dan maksimum formulir unggahan yang berisi hewan yang ingin ia tawarkan untuk diadopsi. Formulir unggahan dapat berisi setidaknya 1 dan maksimum banyak hewan. Sementara hewan hanya terkait dengan 1 formulir unggahan. Kemudian dari data pada formulir adopsi, admin akan memanggil pengguna untuk melakukan wawancara dan kunjungan rumah. Jika calon adopter telah lulus kualifikasi, surat adopsi akan dibuat, bersumber dari data pada formulir adopsi. Kemudian jika masalah ditemukan dan diputuskan bahwa tim MyAnimach akan mencabut hak adopsi, maka formulir daftar hitam akan dibuat yang datanya akan diambil dari formulir adopsi.

C. Persyaratan Data

Daftar beberapa persyaratan data penting termasuk:

1) User (userId, name, email, password, phoneNumber, dob, address, role)

2) Animal (animalld, type, name, description, photo) 
3) Upload (uploadId, date, status, photo)

4) DetailUpload (uploadId, animalId, qty)

5) AdoptionForm (adoptionFormId, userId, animalId, date, status)

6) BlacklistForm (blacklistFormId, adoptiomFormId, date, reason)

7) InterviewForm (interviewFormId, adoptionFormId, date, description)

8) HouseVisitForm (houseVisitFormId, adoptionFormId, date, description)

9) AdoptionLetter (adoptionLetterId, adoptionFormId, date, sign)

\section{KESIMPULAN DAN SARAN}

Dengan menyediakan platform bagi orang-orang yang ingin menawarkan hewan untuk diadopsi dan calon pengadopsi untuk bertemu, myAnimach berpotensi membantu mengurangi jumlah hewan terlantar. Dengan menggunakan aplikasi seluler sebagai media, calon pengadopsi dapat mengakses aplikasi ini dari perangkat seluler mereka di mana saja. Aplikasi ini juga memungkinkan orang-orang yang ingin menawarkan hewan untuk diadopsi untuk mengunggah informasi ini dari perangkat seluler mereka dan membuat proses adopsi menjadi tidak terlalu membosankan.

Untuk pengembangan di masa depan, forum untuk diskusi antar pengguna akan bermanfaat untuk sarana komunikasi yang lebih mudah. Selain itu, fitur baru untuk melaporkan hewan peliharaan yang hilang berpotensi berguna karena dari penelitian sebelumnya, kadang-kadang tidak semua hewan terlantar ditinggalkan. Beberapa dari mereka adalah hewan peliharaan yang hilang dan pemiliknya tidak dapat menemukannya.

\section{DAFTAR PUSTAKA}

[1] Mustafidah, H., Amin R., and Fatimah, V. A. N. (2018). Expert system for determining the type of cats and how to care them. In 3rd Annual Applied Science and Engineering Conference (AASEC 2018).

[2] Amendie, J. (2015). The impact of social media on societty. Santa Clara University (pp 3-5).

[3] Hwe, T. T. (2015). Pembuatan aplikasi web ani-care dengan fitur pelaporan berbasis android. CALYPTRA 4.1 (pp. 1-7).

[4] Vani, M. L. V. R., Kumari, M. C., Priya, M. H., and Harika, N. (2015). An effective language for object oriented design-uml(unified modeling language). In International Research Journal of Engineering and Technology (IRJET 2015) (Vol. 2(5), no. 1212-1218).

[5] Febres, J., Brasfield, H., Shorey, P. R., and Stuart, G. L. (2014). Adulthood animal abuse among men arrested for domestic violence. Violence Agaist Women (Vol. 20(9), no. 10591077).

[6] Pinillls, R. G., Appleby, M. C., Manteca, X., Scott-Park, F., Smith, C., and Velarder, A. (2016). One welfare - a platform for improving human and animal welfare. The Veterinary Record (Vol. 179, no. 412-413).

[7] Newberry, M. (2017). Pets in danger: Exploring the link between domestic violence and animal abuse. Aggression and Violent Behavior (Vol. 34, no, 273-281).

[8] Browne, J. A., Hensley, C., and McGuffee, K. M. (2016). Does witnessing animal cruelty and being abused during childhood predict the initial age and recurrence of commnitting childhood animal cruelty. In International Journal of Offender Therapy and Comparative Criminology (Vol. 61(16)).

[9] Hartman C. A., Hageman, T. O., Williams, J. H., and Acione, F. (2015). Intimate partner violence and animal abuse in an immigrant-rich sample of mother-child dyads recruited from domestic violence programs. In Journal of Interpersonal Violence (Vol. 33(6)). 
[10] Lockwood, R., Arkow, P. (2016). Animal abuse and interpersonal violence: the cruelty connection and its implications for veterinary pathology. Veterinary Pathology (Vol. 53(5), no. 910-918)

[11] de Sousa, T. C., Kelvin, L., Neto, C. D., de Carvalho, C. G. N. (2017). A formal semantics for use case diagram via event-b. In Journal of Software (Vol. 12, no. 3).

[12] Kolandaisamy, R., Subaramaniam, K., Kolandaisamy, I. and Siew Li, L. (2016). Stray animal mobile app. Conference: Regional Conference On Sciences, Technology and Social Science (RCSTSS).

[13] Saswadkar, V., Paygude, V., Dudhe, P., Garad P., and Gaikwad R. (2018). Pet care system based on android application. In International Journal of Trend in Scientific Research and Development (IJTSRD) (Vol. 2, no. 2456-6470).

[14] Hwang, B. R., Lee, Y. A., Kim, H. J., Cho, Y. J., Jhun, H., Kim, S. C., Bae, J. S., and Han, J. S. (2016). Survey on the status of abandoned animals in seoul city. In Global Journal of Medical Research: G Veterinary Science and Veterinary Medicine (Vol. 16).

[15] Mcmillan, F., Duffy, D. L., Zawistowski, S. L., and Serpell, J. A. (2014). Behavioral and psychological characteristics of caine victims of abuse. In Journal of Applied Animal Welfare Science (Vol. 18, no. 92-111).

[16] Burchfield K. B. (2018). The nature of animal crime: scope and severity in chicago. Crime \& Delinquency (Vol. 64(14), no. 1904-1924).

[17] Johson, S. A. (2018). Animal cruelty, pet abuse \& violence: the missed dangerous connection. In Forensic Research \& Criminology International Journal (Vol. 6(6), no. 403415).

[18] Christine, M. A., Hadi, W. Kendekallo, A. C., Suryadarma M., and Amesa A. (2016). INGON, web solusi pemeliharaan hewan-hewan terlantar \& sakit. In Jurnal Teknik Informatika dan Sistem Informasi (Vol. 2 no. 2).

[19] El-Sofany, H. F., El-Seoud, S. A., Alwadani, H. M., and Alwadani, A. E. (2014). Development of mobile educational services application to improve educational outcomes using android technology. In International Journal of Interactive Mobile Technologies (Vol. 8 no. 2,), doi:10.3991/ijim.v8i2.3509.

[20] Rahayu, T. (2015). Perlindungan Hukum Terhadap Satwa dari Perdagangan Liar. Universitas Islam Negeri Sunan Kalijaga Yogyakarta.

[21] Monsalve, S., Ferreira, F., and Garcia, R. (2017). The connection between animal abuse and interpersonal violence: A review form veterinary perspective. Research in Veterinary Science (Vol 114).

[22] Susanto, W., Gandha, N. V. (2015). Pusat edukasi tentang hewan peliharaan di kelapa gading. Jurnal Kajian Teknologi (Vol. 11, no. 1).

[23] Tam, C. Santos, D., and Oliveira, T. (2018). Exploring the influential factors of continuance intention to use mobile apps: extending the expectation confirmation model. Information System Frontiers.

[24] Indrawati, V. (2018). Perlindungan Hewan Liar melalui Peraturan Desa di Kabupaten Ponorogo. Universitas Muhammadiyah Ponorogo.

[25] Wijk, A. V., Hardeman, M., and Endenburg, N. (2018). Animal abuse: Offender and offense characteristics. A descriptive study. In Journal of Investigative Psychology and Offender Profiling (Vol. 15, no. 175-186).

[26] Kharisma, R. H. (2017). Perancangan Iklan Layanan Masyarakat Sosialisasi Pencegahan Kekerasan Terhadap Hewan di Pulau Jawa. Universitas Dian Nuswantoro. 